\section{A OClintiral axertmre}

\section{ACUTE GENERALIZING PERITONITIS AND ITŚ TREATMENT.}

Defivered at the Bristol Royal Infirmary.

BY T. CARWARDINE, M.S., M.B., F.R.C.S., HJNORARY SULGEON.

THE treatment of acute generalizing peritonitis has recently undergone marked improvements in methods and results. Fifteen years ago the recovery of a patient with generalized peritonitis was regarded with such wonder that the few Isolated cases were instantly reported in the medical journals. To-day the event is becoming such a common one that a considerable proportion of such cases may by judicious treatment, both at the time of operstion and afterwards, be saved to the community. You have recently had the opportunity of seeing several such cases, and it may be profitable to consider the principles by which good results may be obtained.

I use the tfrm "generalizing" to cover all those case of rapidly spreading peritoneal infection, usually from a primary focus, which come under the care of the surgeon with increasing frequency. A surgeon may not be strictly accurate if he speak of "general" peritonitis, for his opportunities of exploring the remote peritoneal recesees at the time of operation are necessarily limited.

The common sites of origin of such spreading peritonitis are the vermiform appendix, the uterine appendages, and the gastro-duodenal region, by reason of Infection or perforation.

The Abdominar Pools.

Within the peritoneal cavity there are certain potentlal spaces which may become converted into pools by accumulation of fluid therein. Which of these spaces is primarily involved depends upon the site of origin, the effect of gravity, and the guiding direction of the viscera and omentum, both static and peristaltic. When the trouble originates in the pelvis, whether from infection from the uterine appendages or from the vermiform appendix when situated in the pelvis, the conditions are much the same. The accumulation of the infective fluid occupies the true pelvis; the omentum becomes fixed to the diseased focus, and tends still further to localize the fluid by forming an omental roof between the fluid and the rest of the general peritoneal cavity above. In the case of the left uterine appendages there is some little tendency for the fluid to extend upwards to the left. But in pelvic collections generally there is a greater proclivity for any extension of the fluid to pass upwards and to the right, having the omentum and ascending colon to the inner side, until it forms a pool of overflow in the right lumbar region. Thence, with greater extension, the lower abdomen becomes involved, with a very distinct tendency for another pool to form in the left lumbar region, but in front of the descending colon. In diffuse peritonitis arising from the vermiform appendix, much depends upon the individual position of that variable structure. If the appendix be in the pelvis, the course is similar to that already described; and, In fact, in many cases it is almost impossible to distinguish whether peritonitis arises from a pelvic appendix or from the uterine appendages until the abdomen is opened. But if the appendix be situated above the brim of the pelvis, the first infection is in its nelghbourhood, wherever situated, and the ares tends to be localized by that first line of defence, the omentum. There is no definite rule as to the direction of extension eubsequently. The majority of such collections rapidly spread into the pelvis, and unless this be remembered, and particularly if the pelvic collection form a separate loculus, it is apt to be overlooked and give rise to serious complications. In some cases the fluid collects in the right lumbar region, and here, also, it tends to form a distinct pool separated from the pelvic one by the distended caecum, which may become adherent to the parietes. In the rarer cases in which the appendix is naturally situated to the outer side of the ascending colon, a large primary collectlon may form in the right loin. In these, and also in those in which there is a retrocaecal appendix, the recognizable abscess may be purely subphrenic at first ; indeed, appendicitis is one of the commonest causes of subphrenic abscess.

A third important origin for acute generalizing peritonitis is in perforating lesions of the stomach and duodenum, and in infective peritonitis arising from the gall bladder. In any of these the infection of the peritoneum may be general from the first; but this is more common in the case of perforation of a gastric ulcer owing to the sudden escape of undigested food and gastric secretions. The question is only one of degree, for the majority of perforated gastric ulcers lead to some local peritonitis at first. In perforations of the stomach there are certain favourite sites for the accumulation of fluid which demand attention. If the ulcer be on the anterior wall, there will be fluid in this locality ; and there is often at the same time a collection in the pelvis, representing the flaid which has gravitated, and which must be dealt with. If the ulcer be situated on the posterior wall, then the fluid will be found primarily in the lesser sac of omentum, from which it may escape into the greater sac through the foramen of Winslow. Either at first or later on there is a disposition for fluid to accumulate in the right renal pouch, which has a capacity of about a pint, or in the splenic region. As bearing upon the importance of dralning these areas of any accumulation therein, or of inserting drains to anticipate the reasonable probability of such collections forming there, I need only remind you of the frequency of an overlooked abscess in the splenic region as an ultimate cause of death in otherwise successful operations for perforated gastric ulcer.

Concerning perforated duodenal ulcer there is a greater tendency here for the condition to be localized and obscure at first, and there is better opportunity for protective adhesions to form, and, as the duodenum is only partially covered by peritoneum, any ulcer in the uncovered portion perforates into the retroperitoneal cellular tiseue, and gives rise to subphrenic abscess. But note one important point: diffusing infections arising from the duodenum tend to pass downwards in the lumbar region so as to lead to the erroneous diagnosis of appendicitis, and the patient may complain of pain and tenderness in the region of the appendix. This mistake may be made whether the infection take place through the right lumbar peritoneal pool or through the cellular tissue behind the peritoneum. It may be very difficult at times to distinguish peritonitls arising from the appendix from that arising from the duodenum.

The same tendency to limitation of the peritonitis to the rlght lumbar region occurs when it originates from the gall bladder, but there is not such great difficulty in differential diagnosis, for not only will the history help, but cholecystitls is usually present, with superficial and localized extreme tenderness.

Now, plcture to your mind any of these cases. There is, first of all, the infective focus, whether it be a sloughing appendix, infective appendages, or a perforating ulcer. Around this is a collection of fluld, commonly called an abscess; and, in the diffusing cases of which we are speaking, there is an irregular halo of peritoneal exudation, to which I will specially draw your attention. This is sometimes very abundant, and tends to occupy the peritoneal pools already referred to, and I have found by experience that the serous collections beyond the area of pus formation are deserving of the greatest respect. It is now my practice, if, after liberating a purulent collection, I am in doubt as to whether there be a serous collection in any of the favourite pools, to pass a swab, held by long sponge forceps, into any likely recess for exploratory purposes and for liberation of any serum by adequate drainage. One might be open to the criticism in this procedure that there would be likelihood of seriously damaging the more healtby parts of the peritoneum; but, in the diffasing cases to which we refer, an increasing experience shows the fallacy of such argument. It is the more likely that such exploration will be productive of good by the discovery of and provision for the drainage of the stagnant pools. Moreover, if they be not discovered at the time, the probabilities are they never will be, and the patient will succumb to residual peritonitis.

Accordingly, the practice which I should commend is to drain the serous collections as well as the purulent ones, and, if there be any ar prehension of subsequent infection of any proximate favourite site, to anticipate this by putting a drainage tabe into that area, the 
favourite pools being pelvic, right and left lumbar, and right and left subphrenic.

\section{Abdominal Dratnagr.}

Now as to the direct application of these principles to certain special instances. In perforated gastric ulcer I pass a tube to the region of perforation; if there be any fluid in the pelvis a suprapubic drain is inserted; and in all cases, whether fluid be found there or not, I prefer to drain the right renal pouch, and particularly the splenic reglon, by transfixion through the loin (Fig. 1). In perforated duodenal ulcer the right lumbar region is drained, and if there be much extension of flaid a tube is passed through the right illac region into the pelvis. In collections which are purely pelvic I usually pass two tubes to the bottom of the pouch of Douglas, insert a large piece of oiled silk beneath the small intestines and omentum, which are meanwhile retracted upwards by the left hand in the abdomen, and then place some iodoform gauze between the oiled silk and tabes (Fig. 3). This applies to suppurative pelvic peritonitis, whether arising from the appendix or the appendages. The advantage of passing two tubes, like a double-barrelled gun, is that they can be utillzed for subsequent irrigation of the pelvis, the one being an inlet and the other an outlet. I prefer to pass these in apposition, for if thls be not done they tend to be separated by intra-sbdominal pressure, lymph, and adbesions, so that the irrigating flaid will not pass from one tube to another. For this reason orilns pas se d through the right and left iliac regions respecti / ly (Fig. 2) are not so satisf sctory. In pelvic ca 'es abdominovaginal dralnage is very dependent and satisfactory (Fig. 5); but it has the distinct and inconve nient disedven tage of sometimes leaving a peraistent fistula discharging in to the vagins. Hence I much prefer, a f t er adequat experlence of both, the double-barrelled ventral drainage, with subsequent ircigation (Fig. 3 and Fig. 4, c). For the same reason also I prefer this double-barrelled drainage of the pouch of Douglas to abdominovaginal drainage through the right lliac reglon associated with $a$ short tube in the left iliac region (Fig. 5).

There are certain cases of appendicitis in whlch, in the later stages, there are two localized abscesses-the one in the right iliac or lumbar region, the other occupying the pouch of Douglas. Such I drsin in the right loin, and by passing the finger over the brim of the pelvis burrow into the pelvic collection, inserting two tubes therein (Fig. 4, $a$ and $c$ ), or else drain them separately, the former in the right lliac region, the latter through the vagina or rectum (Fig. 6).

In a more generalized case of diffased peritonitis, involving the lower abdomen and pelvis and both flanks, I would first liberate the fluid from the lower abdomen, then pass a sponge-holder and $\mathrm{swab}$ into the right lumbar region, whence one might liberate as much as a pint of sero-pus from the hypochondrlum, either above or below the liver. Then I would pass a long pair of artery forceps into the loin, high up and far back, making the points prominent, Inclsing on to them, and on their withdrawal bring a large plece of drainage tube through the loin by that means (Fig. 4, a) $\Delta$ similar' procedure would be adopted in the left loin (Fig. $4, b$ ). Then I would pass two

adjacent large tubes into the bottom of the pelvis, and above them a piece of iodolorm gauze, which is prevented from sticking to the uplifted intestines and omentum by a large piece of nicelp-adjusted oiled silk (Fig. 4, c). You will note my predilection for rubber drainage tubes, and although gauze has its advocates for abdominal drainage and I have given it a good trial, I am not in favour of it for its capillarity is destroyed as soon as it is sodden, and I have often observed that it acts as a dam rather than as a drain, its removal being followed by a free discharge of pent up pus. Moreover, it soon becomes very adherent, its meshes become impregnated with coagulated lymph, and its early removal is very tedious and painful.

\section{RECENT IMPROVEMRNTS}

There are two recent improvements in the treatment of these cases which deserve more than passing notice-the Fowler position and the Murphy treatment. The former consists in placing the patient in the upright sitting position as soon as poseible at the time of or immediately after operation, so that the peritoneal exudation may gravitate to the lower abdomen, where drainage is provided for, away from the more dangerous epigastric areas. The method was published by Dr. George Ryerson Fowler of Brooklyn in 1900. A few years later, in 1904, Dr. Murphy explained his methods at a meeting of the American Medical Association, by which he had obtained 8 large percentage of recoveries; and although many surgeons had carried ont his procedure from time to time. the greatest credit is due to him for establishing a rational line of treatment for a condition which was formerly so hopeless.

In the Murphy treatment the proceeding a are adopted in conjanction with the Fowler position. The principles involved are: (1) Rapid removal of the focus, with little disturbance of the peritoneum, and closure of the hole in the

Fig. 6.- Lumbar and gut ; (2) drainage - (a) suprapublc, (b) through the
operation incision; (3) rapid operation, preferably through operation incision; ( 3 ) rapid operation, preferably through
the rectus, and no sutures are put in ; (4) no food is given by the mouth for two or three days ; (5) continuous saline infusions by the rectum, which are administered by means of an irrigator and short vaginal nozzle having several lateral openings. They appear to reverse the lymph current in the peritonenm, to incresse the peritoneal flow, to stimulate the heart and kidneys, and cause a greater eliminative excretion of urine. The object is not to cause the bowels to act, but merely to keep a supply of a few inches of saline fluid always in the rectum. Consequently, as a rule, the top of the fluid in the irrigator should not be more than 4 to 6 in. above the level of the anus. Milk or other suitable nutriment may be added. I regard this continuous rectal infusion as one of the most valuable suggestions of recent times. From 12 to 20 pints of fluid may thus be absorbed in the first twenty-four hours; the patient assumes a natural lively expression, and the tongue becomes moist. One has only to contrast the appearance of the patlent under these measures with that under the former treatment-the dry tongue, restlessness, insatiable thirst-to appreciate its value. With all the main features of this treatment I agree, but scarcely with that of as little disturbance of the peritoneum as possible; for one has become bolder in that respect, as already stated, and I have every reason to be satisfied with the results. 
AFTER-TREATMENT.

The patlent will now require watchful a!tention for some weeks to detect and treat any of the many varied complications which may arise. The first of these is excessive distension, usually most marked in the epigastrium, with a tendency to vomit. This must be vigorously treated by turpentlne enemata, two or three times a day if necessary, by the regular use of a rectal tabe, and by gastric lavage if necessary. By the time the excessive distension is subsiding, there may be indications of considerable septic absorption, in the dry brown tongue, dry wounds, and fetor of the discharges. This is best treated by the administration of calomel and sallnes, by irrigation of the pelvic peritoneum with a weak solution of tincture of iodine decolorized by a few drops of 1 in 20 carbolic acid, and by the insertion of a little iodolorm, aristol, or calomel into the septic focus.

The wounds have a great tendency to become dry, and $I$ am convinced that wet antiseptic applications are better than dry or sterile ones, and I find iodoform ganz 9 to be much more satisfactory than cyanide gauze. Lastly, the discharges are enticed into the dependent parts, and the drainage tubes left out in order from above downwards, those in the pelvis remaining until all foul discharge has ceased and there is no danger of the wound closing over a pelvic collection. Then it is necessary to keep an everwatchful eye on the areas of possible remote infection. Chiefly one must watch, and if in doubt explore with a syringe, for any subphrenic or hepatic abscess, or for empyema. Though more common on the right side, left subphrenic abscess or empjema may occur after appendicitis, but left-sided remote trouble is more common atter perforated gastric ulcer. There are other complications, such as thrombosis of the left femoral vein, septic pneumonia, intestinal obstruction, or ventral hernia which will require appropriate treatment; but if all go on well the patient usually becomes markedly emaciated at first, followed during convalescence by excessive fattening, and for some time dietetic discretion is desirable, owing to the intestinal matting brought about by the peritonitis, but which is fortunately largely recovered from in the course of time.

I have ventured to bring this matter before you as one of extreme surgical importance. Statistics cannot convey the same solid convictions as experience; but you have seen some of the results, and will probably agree with me that the statement that more than half of the cases of widely-generalized peritonitis can be saved is a moderate estimate.

RECENT LITERATURE.

Anmuls of Surgery 1906 itis:

Annuls of Surgery. 1506 , vol.

Ibid., 1905, vol. i, 914 .

BRITISH MEDICAL JOURNAL, 1907, vol. i, 1483.

Ibid., 1906, vol. i. 862.

Ibid., 1905, vol. ii. 11i6.

Pneumococcal Peritonitis:

Annals of Surgery, 1904, vol. ii. 698

Jensen: Archiv fur klinische Chirurgie, 1903, vol. 1xx, 91

Brün: Belläge zur klinische Chirurgie, 1903, vol. xxix, 57.

Annals of Surgery, 1907, vol, i, 203

\section{THE DETERMINANTS OF ABORTION AND HOW TO COMBAT THEM.*}

BY JAMES OLIVER M.D., F.R S.EDIN., F.L.S, PHYSICIAN TO THE HOSPITAL FOR WOMEN, SOHO SQUARE, LONDON.

BrFore discussing those conditions which tend to cause abortion it is imperative that we should bave some clear notion of the meaning of this term, and as it is practically impossible for a human fetus of less than twenty-eight weeks to maintain an independent existence, I define abortion as the act whereby an immature and non-viable product of conception is dislodged from the maternal body. It, is clearly a uterine phenomenon. A child ex. pelled from the uterus at any time after the twentyelghth week of gestation may be rearad; the birth of such will not at present concern us.

In accepting this definition it behoves us to note in passing the somewhat injudicious and misleading use of such expressions as tubal abortion and missed abortion. By the latter it has been customary to designate those cases

* Read before the Walthamstow Division of the British Medical Association. in which the product of conception, perishing as a rule at an early stage of its existence, is not forthwith expelled from the uterus, but continues its sojourn in this organ for weeks, or even months, aft:r the time that we naturally looked for its expulsion. The abortion is unduly delayed, but it will most assuredly be effected, and such a phenomenon should not be designated a missed, but merely a postooned, abortion. Not infrequent]y the fertilized ovum becomes arrested in the Fallopian tube and proceeds to develop therein. Lodged here, the oö эperm is always seriously handicapped and most disadvantageously circumstanced. With a keen struggle it occasionally attalns maturity, but more usual]y it perlshes at an early stage of its existence, and as no provision is made for its natural escape from the mother's body it may for an indefinite time remain concealed therein and be to all concerned a missed abortion. If, again, the fetus should chance to arrive at maturity outside the uterus, delivery cannot be effected except by surgical intervention, and veritably this constitutes a case of missed labour. "Tubal abortion" is not, and never can be, a commendable designation, since it is only available for use aiter the abdominal cavity has been opened, and even then it may seldom, if ever, be truly appllcable.

Until, comparatively speaking, recent]y, our knowledge of oölogy was very meagre, buc now it has been satis. factorily demonstrated that the ova are corpuscles derived from the superficial germ epithellum, and that they become embedded in the substance of the ovary by a pro. cess of involution of the primitive germ mass. The nucleus of a corpuscle swells ont, and constitutes the germinal vesicle with its contained nucleolus or germinal spot. The cytoplasm around the nucleus increases more or less markedly in amount and forms the yolk, whllst the peripheral portion of the yolk becomes differentiated into a cell wall, the zona pellucida or vitelline membrane. With the age of the ovum this membrane becomes more and more dense and resistant. The Grasfian follicle is a vascular capsule formed by the connective tlssue stroma of the ovary. In its early days it is lined by a single, but afterwards by two or more, layers of cells. These cells, which are derivatives of the connective tissue corpuscles, constitute the membrana granulosa, and secrete a fluid which accumulates and determines eventually the rupture of the Grasfian follicle. In the human female more especially the escape of the ovum from the ovary depends almost entirely upon the activity of these cells. At the time of dehiscence the fimbriated extremity of the Fallopian tube is guided to and grasps the ovary at the seat of rupture, [and thus the ovum is conveyed to the uterus.

It is not yet agreed whether the menstrual discharge is, as I maintain, a secretory product, or, as is usually belleved, an outpouring of blood from capillaries the continuity of whlch has been broken up by a more or less extensive destruction of the uterine mucoss, and the relationship of this phenomenon to ovulation is as perplexing as ever. Undoubtedly the two phenomena are correlated, but ovulation may occur independently of menstruation, and the former cannot in any sense be considered the cause of the latter. During lactation, and whilst menstruation is thereby held in abeyance, conception may and does occasionally take place, and again, superfetation may occur during the evolution of an ectopic pregnancy. This happened recently in a case under my care; the second fertllized ovum had passed by the undisturbed tube to the uterus, and was developing therein.

In estimating the normal duration of gestation in the human female, or the stage of pregnancy reached in any given case, we are accustomed to make our reckoning from the date of the cessation of the last menstrual period. In accepting this dogma we are naturally induced to ask whether the ovum with which we are immediately concerned belonged to the menstrual period from which we date our reckoning or to that which in the ordinary course of events would have succeeded this. On this point we are not yet agreed, but after a most careful scruting of clinical facts, I have come to the conclusion tba; the ovum corresponding to a past menstrual perlod is already too mature to reapond to the influences of a spermatozoon. For the fulfilment of fertilization the ovum must not only attract the gpermatozoa at a distance, but must on the near approsch of one of these bojies throw out a cone-like prosess, and through this so called core of attraction 